\section{The Role of Sex Work Pay in Moderating the Effect of Mobile Phone Solicitation on Condom Practices: An Analy- sis of Female Sex Workers in India}

\section{Navani-Vazirani $\mathbf{S}^{1 *}$, Heylen $\mathrm{E}^{2}$, Deardorff $\mathrm{J}^{1}$, Srikrishnan $\mathrm{AK}^{3}$, Vasudevan $\mathrm{CK}^{3}$, Solomon $\mathrm{D}^{4}$ and Ekstrand $\mathrm{ML}^{125}$}

${ }^{1}$ School of Public Health, University of California, Berkeley, USA

${ }^{2}$ Center for AIDS Prevention, University of California, San Francisco, California, USA

${ }^{3} Y R$ Gaitonde Centre for AIDS Research and Education (YRG CARE), Chennai, Tamil Nadu, India

${ }^{4}$ SHADOWS, Chirala, Andhra Pradesh, India

${ }^{5}$ St. John's Research Institute, Bangalore, Karnataka, India

\begin{abstract}
Mobile phones remain a largely untapped resource in the ongoing challenge to address Female Sex Worker (FSW) health, including HIV prevention services, in India. An important step towards designing effective mobile phone-based initiatives for FSWs is clarifying the contextual influences of mobile phone solicitation on sexual risk behavior. In this paper, we extend previously identified associations between mobile phone solicitation and condom practices by examining whether this association is moderated by sex work pay and offer key considerations for future research and implementation.

Specifically, we conducted an analysis among 589 Indian FSWs, where FSWs who did not use mobile phones to solicit clients had the lowest mean sex work pay (INR 394/ USD 6.54) compared to FSWs who used both mobile and traditional strategies (INR 563/ USD 9.34). Our analysis indicate low paid FSWs who used mobile phones concurrently with traditional strategies had 2.46 times higher odds of inconsistent condom use compared to low paid FSWs who did not use mobile phones for client solicitation. No such effect was identified among high paid FSWs. These findings also identified group level differences among FSWs reporting different mobile
\end{abstract}

*Corresponding author: Navani-Vazirani S, School of Public Health, University of California, Berkeley, CA 94709, USA, Tel: +1 6097212830; E-mail: snavani@gmail.com

Citation: Navani-Vazirani S, Heylen E, Deardorff J, Srikrishnan AK, Vasudevan CK, et al. (2017) The Role of Sex Work Pay in Moderating the Effect of Mobile Phone Solicitation on Condom Practices: An Analysis of Female Sex Workers in India. J AIDS Clin Res Sex Transm Dis 4: 008.

Received: February 01, 2017; Accepted: March 14, 2017; Published: March 28,2017 phone solicitation strategies, including violence, client condom use and HIV status.

Our results indicate that low pay does moderate the association between mobile phone solicitation and condom practices, but only among a sub-set of low paid FSWs. These findings also demonstrate the utility of classification by different mobile phone solicitation strategies for accurate assessment of sexual risk among mobile phone soliciting FSWs. In turn, this paves the way for novel approaches to utilize mobile phones for FSW HIV prevention. We discuss one such example, a mobile phone-based rapid screening tool for acute HIV infection targeting Indian FSWs.

Keywords: Female sex work; HIV prevention; Income; India; Mobile phones; Sexual risk

\section{Introduction}

While mobile phone use among Indian Female Sex Workers (FSWs) to connect with clients have consistently increased, strategies to integrate mobile phones into HIV/AIDS initiatives for FSWs have been limited, particularly in regard to HIV prevention [1-4]. The unique considerations required for sex work populations contribute to the challenge of designing effective strategies [5,6]. Building upon research, which highlights the complex intersection of structural and individual factors contributing to FSW sexual behavior, a more robust understanding of how mobile phones influence FSW sexual behavior may offer unique insights into effective designs for mobile phonebased HIV prevention strategies targeting FSWs $[7,8]$. In this paper, we explore the previously identified associations between mobile phone client solicitation and condom practices with clients, by asking whether these associations differ for high and low-paid FSWs.

Previous research related to mobile phones and female sex workers can largely be classified into two categories: studies that have described and documented the use of mobile phones as a solicitation strategy and studies that have examined effect of mobile phones on FSW sexual behavior, including condom practices with clients [2,3,916]. Examinations of the relationship between mobile phone-based client solicitation and condom practices with clients have consistently demonstrated mobile phone client solicitation is associated with FSW condom practices $[12,14,15]$. Some of this research suggests mobile phones act as a sexual risk for FSWs $[12,14]$. However, later research has demonstrated that mobile phones may serve as a more fluid contextual influence, where mobile phones may act as risk or protection based on how FSWs utilize mobile phones for client solicitation (e.g., solicitation only by mobile phone, in conjunction with venue solicitation, in conjunction with third party broker) [15]. These findings suggest there may be unmeasured contextual factors that modify the relationship between mobile phone-based solicitation and condom practices among FSWs and clients. Based on previous sex work venue-based evidence that FSW economic status influences sexual risk/ protective behavior, we postulate that sex work price may account for differences in inconsistent condom use among mobile phone using FSWs.

\section{FSW economic status and sexual risk/protection}

Research to date has demonstrated that the economic status of a FSW (e.g., low or high paid FSW) is closely linked to how effectively 
a FSW safely navigates within sex work environments and in turn, the level of formal or informal support to enable safe sexual practices with clients [17-23]. This is consistent with findings that economic debt and more generally, economic vulnerability, contributes to HIV risk for sex workers $[1,24]$. Specifically, research indicates higher paid FSWs tend to frequent more controlled condom environments, with more formalized hierarchical structures [19,21,22]. For example, highly paid Ugandan sex workers were more likely to work in environments that enforced specific policies for clients compared to their lower paid peers [19]. Furthermore, more highly paid sex workers may operate with greater autonomy in regard to client selection, whereas lower-paid sex workers may be forced to navigate through more barriers with brokers, such as pimps and madams, as well as more legal barriers related to sex work $[22,25]$.

Venues that do not maintain or enforce policies to regulate client behavior with sex workers (e.g., street based sex work) may provide more risks for violence against sex workers by clients, greater alcohol consumption by clients, less access to condoms as well as less support for sex workers to negotiate condom use with clients [17,18,20-23]. The extent to which these findings apply in the context of widespread mobile phone use as a solicitation method is vastly understudied. Identification of differences between high and low paid FSWs may inform different targets and designs for meaningful and effective mobile phone-based initiatives targeting Indian FSWs.

\section{Chirala and Andhra Pradesh: A setting with both high mo- bile phone solicitation and HIV prevalence}

HIV prevalence among FSWs in Chirala is $4.9 \%$ and in Prakasam district, the HIV prevalence is estimated at $13.4 \%$ [26,27]. These rates are substantially higher compared to national estimates of HIV prevalence of 2.8\% among Indian FSWs [28]. Two key factors appear to contribute to high HIV prevalence rates among general and sex work populations in Chirala [26]. First, Chirala is located along a major trucking route, which has been documented as a source of clients for FSWs. Second, Chirala is a major destination for male migrant workers (in the clothing, tobacco and cannery industries), who frequent sex workers as well as engage in other high risk sexual behaviors associated with unprotected sex, such as alcohol consumption [26,29].

In addition, research that has examined HIV prevalence among FSWs in South India has found HIV prevalence reductions among FSWs, except among mobile phone soliciting FSWs [2]. This suggests potential gaps in reaching mobile phone using FSWs with existing HIV/AIDS strategies. Furthermore, previously reported analysis from Chirala, Andhra Pradesh indicates that mobile phone solicitation for clients is both frequent and diverse in relation to how mobile phones are utilized within sex work environments [15]. Given these factors, Chirala provides an optimal setting to examine whether an association between mobile phone solicitation and condom use is moderated by sex work pay among urban Indian FSWs in order to better inform mobile phone-based HIV prevention strategies for Indian FSWs.

\section{Methods}

\section{Procedures and Sampling strategy}

We examined cross-sectional data to report on mobile phone solicitation practices among 589 FSWs in Chirala, Prakasam district and Andhra Pradesh. The initial phase of this research was qualitative, including social mapping, key informant interviews and screening questionnaires, which provided entry points to access female sex workers directly, as well as third-party agents including Pimps, Brothel managers, Vendors and Drivers, within Chirala and the suburbs of the city. Sampling was conducted at NGO clinics, health fairs, and community outreach events run by NGOs that had previous experience working within the local communities of FSWs. Approximately one third of the sample was recruited from each of these event types. Inclusion criteria required participants to be eighteen or older, to speak the local language (Telugu) or English, and to have engaged in sex work in the area for at least three months, where sex work was defined as exchanging sexually related practices for goods, services, and/or money. Surveys were administered face-to-face by trained interviewers, in locations that guaranteed privacy for participants over the course of the study from 2009-2010.

Data were collected in collaboration by the University of California, San Francisco Center for AIDS Prevention Studies, YR Gaitonde Centre for AIDS Research and Education (YRG CARE) in Chennai and the NGO SHADOWS in Andhra Pradesh. Institutional review board approval (IRB: 10-04971) was granted by the University of California, San Francisco, YRG CARE and the Indian Council of Medical Research.

\section{Statistical Analysis}

Descriptive analyses were performed for the three types of client solicitation: 1) exclusive mobile phone solicitation $(\mathrm{n}=73), 2)$ concurrent mobile phone/traditional strategies $(n=391)$, and 3) no mobile phone solicitation $(n=125)$. Descriptive analyses consisted of frequency tabulations for categorical variables, and calculation of the mean and standard deviation for continuous variables, defined in appendix 1 (Measures). Differences in proportion between the three groups of interest were assessed via Fisher's exact tests, and differences in means via ANOVA.

Then, we used regression models to test the moderation effect of low sex work pay on the relationship between mobile phone solicitation and inconsistent condom use adjusting for key covariates. We assessed this moderation effect among FSWs reporting concurrent mobile phone/traditional solicitation strategies and those who reported no mobile phone solicitation. Due to extreme skewed proportions related to inconsistent condom use among exclusive mobile phone using FSWs, this sub-group from our sample was identified as ineligible for moderation testing. This decision was based upon statistical guidance that indicates an extreme skewed proportion of yes/no responses preclude any meaningful identification and conclusion of how sex work pay may moderate condom practices among this sub-group of mobile phone using FSWs [30].

A multi-level model was constructed to ascertain whether modeling the data with female sex workers nested within the geographic neighborhood, from which they were recruited, compared to single level logistic regression, was warranted. A likelihood ratio test yielded a non-significant test result, which indicated a single-level model was the most parsimonious model for the data.

We ran two single-level logistic regression models for the outcome of interest, inconsistent condom use: first without, then with the interaction term between concurrent mobile phone/traditional solicitation strategies and low sex work pay. All models were adjusted for age, frequency of sex work and recent physical violence. These factors were included based on previous research demonstrating key relevance to condom practices [31-33]. Each regression model maintained 
Citation: Navani-Vazirani S, Heylen E, Deardorff J, Srikrishnan AK, Vasudevan CK, et al. (2017) The Role of Sex Work Pay in Moderating the Effect of Mobile Phone Solicitation on Condom Practices: An Analysis of Female Sex Workers in India. J AIDS Clin Res Sex Transm Dis 4: 008.

Table1: Demographic \& Occupational Profile of Participants by Mobile Phone Solicitation Practices.

\begin{tabular}{|c|c|c|c|c|}
\hline & $\begin{array}{l}\text { No Mobile Phone Solicitation } \\
(n=125)\end{array}$ & $\begin{array}{l}\text { Concurrent Mobile Phone/ } \\
\text { Traditional Solicitation } \\
(\mathrm{n}=391)\end{array}$ & $\begin{array}{l}\text { Exclusive Mobile Phone } \\
\text { Solicitation }(n=73)\end{array}$ & $\begin{array}{l}\text { Group Comparisons } \\
(\mathrm{N}=589)\end{array}$ \\
\hline & mean (SD) & mean (SD) & mean (SD) & Anova ( $p$ value) \\
\hline Age in years (18-55) & $29.7(0.61)$ & $29.1(0.29)$ & $28.8(0.68)$ & 0.503 \\
\hline Years of sex work ${ }^{a}$ & $6.7(0.56)$ & $5.6(0.24)$ & $4.0(0.48)$ & 0.028 \\
\hline \multirow[t]{2}{*}{ Sex work pay } & $394.00(33.36)$ & $563.22(25.34)$ & $553.42(73.08)$ & 0.003 \\
\hline & n (\%) & n (\%) & n (\%) & Fisher Exact Test ( $p$ value) \\
\hline Education $\leq$ primary school & $113(90.4)$ & $322(82.3)$ & $63(86.3)$ & 0.089 \\
\hline Slum residence & $42(33.6)$ & $198(50.6)$ & $59(80.8)$ & 0.000 \\
\hline $\begin{array}{l}\text { Engagement in sex work }>1 \mathrm{x} / \\
\text { week }\end{array}$ & $100(80.0)$ & $320(81.8)$ & $33(45.2)$ & 0.000 \\
\hline $\begin{array}{l}\text { Physical violence by any sexual } \\
\text { partner, past } 12 \text { months }\end{array}$ & $44(35.2)$ & $213(54.4)$ & $11(15.0)$ & 0.000 \\
\hline Ever (any) violence by client & $89(71.2)$ & $303(77.4)$ & $43(58.9)$ & 0.004 \\
\hline $\begin{array}{l}\text { Sex Work Income }<350 \\
\text { Rupees }\end{array}$ & $72(57.6)$ & $162(41.4)$ & $26(35.6)$ & 0.002 \\
\hline $\begin{array}{l}\text { Inconsistent condom use with } \\
\text { clients, past } 30 \text { days }^{b}\end{array}$ & $43(36.4)$ & $172(45.1)$ & $1(1.4)$ & 0.000 \\
\hline $\begin{array}{l}\text { Reported STI testing, other } \\
\text { than HIV, in the past } 3 \text { months }\end{array}$ & $46(36.8)$ & $183(46.8)$ & $24(32.8)$ & 0.026 \\
\hline $\begin{array}{l}\text { STI diagnosis, other than HIV, } \\
\text { past } 3 \text { months among tested }\end{array}$ & $\begin{array}{l}\text { tested \& negative: } 12(26.0) \\
\text { tested \& positive: } 34(73.9)\end{array}$ & $\begin{array}{l}\text { tested \& negative: } 15(8.2) \\
\text { tested \& positive: } 168(91.8)\end{array}$ & $\begin{array}{l}\text { tested \& negative: } 1(4.1) \\
\text { tested \& positive: } 23(95.8)\end{array}$ & 0.002 \\
\hline Reported ever HIV test & $112(89.6)$ & $380(97.1)$ & $72(98.6)$ & 0.001 \\
\hline $\begin{array}{l}\text { Ever HIV diagnosis status } \\
\text { among tested }\end{array}$ & $\begin{array}{l}\text { tested \& negative: } 96(85.7) \\
\text { tested \& positive: } 16(14.2)\end{array}$ & $\begin{array}{l}\text { tested \& negative: } 359(94.4) \\
\text { tested \& positive: } 21(5.5)\end{array}$ & $\begin{array}{l}\text { tested \& negative: } 70(97.2) \\
\text { tested \& positive: } 2(2.7)\end{array}$ & 0.004 \\
\hline
\end{tabular}

a= Missing data among FSWs who reported no time measure to reflect initiation of sex work. Among no mobile phone group, 2 missing responses $\&$ among concurrent mobile phone/ venue-based solicitation group, 3 missing responses.

$b=$ Missing data among FSWs who reported no vaginal sex with clients in previous 30 days. Among no mobile phone group, 7 missing responses; Among concurrent mobile phone/ traditional solicitation group, 10 missing responses; Among exclusive mobile phone-based group, 4 missing responses.

Variance Inflation Factors (VIF) $<10$ and statistical significance was determined based on ninety five-percent confidence intervals for all models [34]. All statistical analysis was conducted in STATA version 12 .

\section{Results}

The demographics and sex work related characteristics of the sample $(\mathrm{N}=589)$, stratified by client solicitation method are summarized in table 1. All variables except age and education were significantly different between the groups. The 'no mobile phone solicitation' group reported the lowest mean sex work price (INR 394/USD 6.54) compared to FSWs who used mobile phones and traditional solicitation strategies concurrently (INR 563/USD 9.34) and exclusive mobile phone solicitation (INR 553/USD 9.17). Findings also indicated that FSWs who reported no mobile phone use had the longest mean duration of sex work (6.7 years) as opposed to FSWs who used mobile phones exclusively for solicitation (4.0 years). Eighty percent of the women who did not use any mobile phones for client solicitation and $81.8 \%$ of women who used both methods reported sex work more than once a week. In contrast, only forty-five percent of exclusive mobile phone users reported working this frequently. Significant differences were also found in regard to physical violence reported in the previous twelve months, with exclusive mobile users showing the lowest proportion (15\%), followed by the no mobile phone group (35\%) and concurrent mobile phone/traditional solicitation (54\%). Among those FSWs who reported vaginal sex with clients in the previous thirty days, forty-five percent of concurrent mobile phone/traditional solicitation FSWs reported inconsistent condom use with clients, compared to thirty-six percent of those not using mobile phones for solicitation and $1.4 \%$ of those only using mobile phones for client solicitation. Exclusive mobile phone sex workers reported the lowest rates of STI testing in the previous three months (32.8\%). In addition, lifetime self-reported HIV testing was reported by at least $89.6 \%$ of sex workers in all three groups and a greater proportion of the no-mobile group reported being HIV infected (14.2\%) than did the women in the other two groups (exclusive mobile phone solicitation: $2.7 \%$ and mobile phone/traditional solicitation: 5.5\%).

Logistic regression models were constructed with inconsistent condom use as the outcome variable and type of solicitation practice and low sex work income as key independent variables. Results are shown in table 2. Model 1 shows a logistic regression model of concurrent mobile phone/traditional solicitation (reference: FSWs reporting no mobile phone use for client solicitation), low sex work pay and control variables prior to introducing the moderation term. Model 2 tested whether there was an interactive effect of low sex work income by concurrent mobile phone/traditional solicitation on condom practices with clients.

In model 1, FSWs with concurrent mobile/traditional solicitation strategies demonstrated over 1.5 higher odds of inconsistent condom use compared to FSWs who did not report any mobile phone-based client solicitation, but the Odds Ratio (OR) was not statistically significant (OR: 1.53 95\%; CI: 0.94-2.49). Younger age, recent physical violence, high frequency of sex work and low pay were significant 
Table 2: Logistic regression models of concurrent mobile phone/traditional solicitation strategies and low pay on inconsistent condom use ( $\mathrm{N}=499)$.

\begin{tabular}{|l|l|l|}
\hline Parameter & $\begin{array}{l}\text { Model 1: } \\
\text { OR (95\% Cl) }\end{array}$ & $\begin{array}{l}\text { Model 2: } \\
\text { OR (95\% Cl) }\end{array}$ \\
\hline $\begin{array}{l}\text { Intercept } \\
\text { (Outcome: Inconsistent Condom Use) }\end{array}$ & $0.10(0.04-0.23)$ & $0.16(0.07-0.42)$ \\
\hline Concurrent Mobile Phone/ Traditional Solicitation (Ref: No Mobile Phone Solicitation) & $1.53(0.94-2.49)$ & $0.77(0.38-1.59)$ \\
\hline Age & $0.96(0.93-0.99)$ & $0.96(0.93-0.99)$ \\
\hline Recent Physical Violence & $2.44(1.60-3.72)$ & $2.41(1.57-3.68)$ \\
\hline High frequency of sex work (> once a week) & $3.58(1.83-7.01)$ & $3.87(1.96-7.64)$ \\
\hline Low Sex Work Pay (<=350 Rupees) & $3.35(2.23-5.03)$ & $1.37(0.60-3.13)$ \\
\hline Low Sex Work Pay ${ }^{*}$ Concurrent Mobile Phone \& Traditional Solicitation Strategies & & $3.20(1.23-8.30)$ \\
\hline
\end{tabular}

predictors of inconsistent condom use. Model 2 demonstrated a statistically significant interaction effect between low pay for sex work and concurrent mobile phone/traditional solicitation. Specifically, the effect of low sex work pay for FSWs soliciting via concurrent mobile phone/traditional strategies was 3.20 times the effect of low sex work pay for FSWs not using mobile phones, after adjustment.

Further interpretation of the interaction odds ratio indicated that among low paid FSWs, those who used mobile phones and traditional solicitation strategies had 2.46 times higher odds of inconsistent condom use compared to low paid FSWs who did not use mobile phones for client solicitation. But among high paid FSWs, the odds of inconsistent condom use for those soliciting via both mobile phone and traditional strategies were not significantly different from the odds for FSWs not soliciting clients via mobile phone $(\mathrm{OR}=0.77,95 \%$ CI 0.38 -1.59 ).

\section{Discussion}

This study examined whether sex work pay moderated the relationship between mobile phone solicitation and condom practices with clients. We demonstrate that sex work pay does moderate the association between mobile phone solicitation and condom practices, but only among a sub-set of low paid FSWs who reported dual solicitation strategies using traditional and mobile phone methods. We also identified group level differences in regard to demographic and occupational factors between two groups of FSWs, reporting different mobile phone solicitation strategies. Our findings indicate a new framework, one that incorporates classifications for different mobile phone solicitation strategies, is needed to accurately assess emerging risks within sex work environments for Indian FSWs. We discuss the specific implication of our findings below and potential strategies to translate this research into practice.

Specifically, our findings demonstrated that low paid FSWs, who reported dual mobile phone and traditional solicitation strategies, had over two times higher risk of inconsistent condom use compared to low paid, non-mobile phone using FSWs. The fluidity of this finding, where only a sub-set of low paid FSWs were most at risk for inconsistent condom use, stands in contrast to traditional frameworks of sex work environments, where economic status and type of solicitation strategy inform relatively fixed socio-environmental influences on FSW condom practices $[17,19-22]$. Our findings underscore a need to devise more compatible frameworks to assess risks within sex work environments, which account for the varied effects of mobile phones on FSW condom practices.

We postulate two potential reasons that may contribute to this increased vulnerability for low paid FSWs who solicit via traditional and mobile phone strategies. First, low paid FSWs who solicit using traditional practices, such as brothels, street or brokers, may use mobile phones as a way to supplement their sex work income. For this group, mobile phone use may offer opportunities to earn sex work income without having to share profits to third party brokers and this may result in FSWs more willing to engage in high-risk sexual behavior with clients [1].

Second, the use of mobile phones as a supplemental solicitation practice as opposed to a primary method of solicitation, may translate into less protective mechanisms in place for FSWs. For instance, previous research has identified FSWs who use of mobile phones exclusively for client solicitation developed sophisticated peer-based networks for client referrals [10]. In contrast to this, FSWs using dual mobile phone and traditional strategies may not be investing effort and time into building such mobile phone-based networks of clients. This may result in less ability to screen out high-risk clients compared to FSWs who are using mobile phones exclusively. While these rationales require further study and confirmation, we believe they demonstrate a line of enquiry into understanding a new, more hidden sexual risk environment for FSWs that are not often captured with traditional FSW research and practice strategies $[1,4]$.

Furthermore, our findings of group level demographic and occupational differences based on type of mobile phone solicitation are consistent with global evidence of variable sexual risk/protective associations based on different mobile phone utilization strategies. These patterns have emerged among sexually hidden populations, including FSWs, adolescents and Men having Sex with Men (MSM) in India and globally [15,35-39]. Building upon this evidence, a classification based on different mobile phone solicitation practices may inform new frameworks to assess risks and protections within increasingly hidden and mobile phone-driven sex work environments.

In this paper, we assessed group level differences in order to better understand the contextual differences that different mobile phone utilization strategies may reflect. We report on two distinct groups below: FSWs using mobile phones exclusively for client solicitation and FSWs who reported using both mobile phones and traditional strategies for client solicitation.

\section{Sexual behavior profiles among sex workers, by mobile phone solicitation}

Exclusive mobile phone solicitation: Sex workers in this group were more likely to report slum residence, the lowest frequency of sex work and the lowest physical violence in the previous twelve months as well as lifetime physical violence by clients. This group also reported significantly lower rates of recent STI testing (33\%), compared to 
FSWs who reported concurrent mobile phone and traditional solicitation strategies (47\%). This may be due to less contact with NGO referral networks or less access to STI testing services, which are often linked to traditional sex work venues [13].

In addition, only one of 73 exclusive mobile phone users reported inconsistent condom use. This may be indicative of a specific protective pattern of condom practices among exclusive mobile users. For example, increased control that FSWs can exert in screening and selecting clients for themselves versus a third person broker influencing client selections may contribute to this protective pattern. Exclusive mobile phone users may represent a type of FSW who has attained higher status among clients or maintain a different type of occupational support and referral system compared to other FSWs [10]. Future research is required to confirm these patterns.

Concurrent mobile phone/traditional solicitation: Sex workers who reported concurrent mobile phone/traditional solicitation practices reported the highest frequency of sex work and the highest rates of physical violence in the previous twelve months as well as lifetime physical violence by clients. This group also reported the highest rates of inconsistent condom use and the highest rates of STI testing, which may account for high rates of recent STI-positive diagnoses. As discussed earlier, we conjecture this group of FSWs may encounter specific risks by navigating between traditional and mobile phone solicitation strategies, including using mobile phones as a supplement to venue or broker based strategies. As a supplemental form of solicitation, FSWs may not seek out the peer based mobile networks that other mobile phone FSWs may establish [10]. This may offer less screening and less protection for FSWs with clients.

\section{Next Steps: Designing mobile phone-based tools for FSWs}

Emerging research indicates that the sophistication among sex workers, in respect to both mobile phone use and HIV/AIDS, requires moving beyond basic HIV/AIDS messaging to more substantive and empowering tools for sex workers $[1,6]$. In this paper, we identify a particular subset of FSWs, low paid FSWs who reported mobile phone and traditional solicitation strategies as most at risk for inconsistent condom practices. Moving forward, we ask three key questions: How best can mobile phone strategies compliment existing HIV/AIDS services? What are the design parameters that would enable FSWs to utilize these resources safely? And what are the central concerns that would motivate this sub-set of FSWs to consult with mobile phone based resources?

An integral part of any mobile phone intervention design is to ensure the privacy and safety for sex workers [5,6]. Misdirection built into the design can ensure that any person who picks up a phone of a FSW is not alerted to their status as a sex worker. For instance, a general women's health interactive health mobile phone application that includes FSW relevant tools and information, may provide such misdirection. In the case of male sex workers or male clients as a target for mobile phone-based HIV/AIDS tools or information, a counterpart would be development of a general men's health application.

A possible secondary benefit of this misdirection strategy is collection of anonymous health data to inform predictive health algorithms for sex workers. Such algorithms could be powerful resources for FSWs if they are both informative and empowering to guide their own sexual decision making with sexual partners, including non-paying partners. For instance, work on developing acute HIV algorithms in Sub-Saharan Africa have been effective at detecting HIV infections before current HIV tests provide a positive diagnosis (e.g., before HIV antibodies are detectable in the body) but when HIV infectivity to sexual partners is high [40]. This work demonstrates a proof of concept that among high-risk populations, easily accessible information (e.g., age 18-29 years, fever, fatigue, diarrhea, body pains, sore throat and GUD) can yield valuable results to identify individuals earlier and to reduce HIV transmission to client and non-client sexual partners when individuals may be highly infectious [40]. Adaptation of this work into a mobile phone-based platform for an Indian context has the potential to strengthen existing HIV/AIDS services and develop new pathways for FSW empowerment and HIV/AIDS education, which moves beyond the basic messaging related to HIV, including condom use for FSWs.

Finally, any design for mobile phone-based strategies require substantial input from sex workers themselves. Our example was identified as a feasible and relevant strategy in consultation with urban FSWs and community based organization staff in Mumbai and Bangalore in 2015. Through this process, FSWs noted motivation to use a mobile phone-based rapid screening tool for acute HIV infection as a strategy to keep their non-paying partners infection free. Such consultations are important starting points to inform design considerations. However, constant vetting with sex workers are essential to ensure safety and effectiveness.

\section{Limitations}

Limitations of this study include the potential for socially desirable responses across all groups examined and the non-random sampling strategies employed. The non-random sampling strategy prevents us from generalizing our findings to the population of all female sex workers in the region. However, research among sex work populations requires striking a balance between rigor of evidence, safety and ethical participation of sex workers [41]. The direct enumeration of sex workers needed for a probability sample is a barrier from a safety and ethical perspective for sex workers. In addition, it poses unique logistical and financial challenges to enumerate all sex workers in the study area. Instead, social mapping, the involvement of gatekeepers and key informants led to the participation of a wide range of sex workers.

In addition, our study was limited in that the data had insufficient power to examine effects of sex work pay on client condom practices among FSWs who reported exclusive mobile phone use for client solicitation [30]. However, we were able to confirm group level differences among FSWs who used different types of mobile phone strategies. We suggest these demographic and occupational differences are relevant to HIV risk and in turn, for mobile phone-based HIV prevention intervention strategies. Given this, we reported on group level findings to inform future research on exclusive mobile phone users as well as FSWs who use different types of mobile phone-based strategies for client solicitation.

\section{Conclusion}

This study offers new evidence to suggest low sex work pay moderates the previously demonstrated associations between mobile phone-based solicitation and FSW condom practices with clients but only among low paid FSWs reporting dual traditional and mobile phone solicitation strategies. While further study is required to generalize these findings, this study demonstrates classifications of different mobile phone strategies and sex work pay are important factors to consider when designing FSW research, practice and policy. In particular, research and programming frameworks that 
Citation: Navani-Vazirani S, Heylen E, Deardorff J, Srikrishnan AK, Vasudevan CK, et al. (2017) The Role of Sex Work Pay in Moderating the Effect of Mobile Phone Solicitation on Condom Practices: An Analysis of Female Sex Workers in India. J AIDS Clin Res Sex Transm Dis 4: 008.

incorporate different mobile phone solicitation strategies can yield important new insights into shifting socio-environmental factors contributing to sexual risk behavior among mobile phone soliciting FSWs. This study provides a proof of concept that such a framework can offer particularly useful distinctions to identify HIV vulnerabilities among FSWs.

Moving forward, our example, a mobile phone-based rapid screening tool for acute HIV infection, offers an approach to meaningfully integrate mobile phone-based tools into existing HIV/AIDS services. In addition, this novel example outlines an approach to empower and inform sex workers via low-cost and quickly scalable technology. The key to this is identifying a setting that is uniquely positioned to integrate HIV prevention mobile phone-based tools for sex workers.

\section{Acknowledgements}

The authors wish to acknowledge the important collaboration and contribution of the entire study staff at SHADOWS, Shelter and YRGCARE. The authors also wish to extend their deepest gratitude to the participants, who were extremely generous in sharing their time and experiences with the study teams. The authors also extend their sincere gratitude to Dr. Emily Ozer and Dr. Adrian Aguilara for their insights to the paper and to the staff and affiliates of Swasti in Bangalore and Mumbai for engaging in design consultation discussions. Finally, the authors acknowledge the funding support from the US National Institute on Alcohol Abuse and Alcoholism [5R01AA015298, M. Ekstrand, PI].

\section{References}

1. Bandewar SV, Bharat S, Kongelf A, Pisal H, Collumbien M (2016) Considering risk contexts in explaining the paradoxical HIV increase among female sex workers in Mumbai and Thane, India. BMC public health 16: 85

2. Isac S, Ramesh BM, Rajaram S, Washington R, Bradley J, et al. (2015) Changes in HIV and syphilis prevalence among female sex workers from three serial cross-sectional surveys in Karnataka state, South India. BM Open 5: 007106

3. Jayaraman GC, Kumar S, Isac S, Javalkar P, Gowda PR, et al. (2013) Demographic changes and trends in risk behaviours, HIV and other sexually transmitted infections among female sex workers in Bangalore, India involved in a focused HIV preventive intervention. Sex Transm Infect 89: 635-641.

4. Wilson D (2015). HIV programs for sex workers: lessons and challenges for developing and delivering programs. PLoS Med 12: 1001808.

5. Sambasivan N, Weber J, Cutrell E (2011) Designing a phone broadcasting system for urban sex workers in India. In: Proceedings of the SIGCHI Conference on Human Factors in Computing Systems. Association for Computing Machinery, New York, USA. Pg No: 267-276.

6. Thomas B, Closson EF, Biello K, Menon S, Dhanalakshmi A, et al. (2015) Development and Open Pilot Trial of an HIV-Prevention Intervention Integrating Mobile-Phone Technology for Male Sex Workers in Chennai, India. Arch Sex Behav.

7. Shannon K, Goldenberg SM, Deering KN, Strathdee SA (2014) HIV infection among female sex workers in concentrated and high prevalence epidemics: why a structural determinants framework is needed. Curr Opin HIV AIDS 9: 174-182.

8. Tan SY, Melendez-Torres GJ (2016) A systemic review and metasynthesis of barriers and facilitators to negotiating consistent condom use among sex workers in Asia. Cult Health Sex 18: 249-264.

9. Buzdugan R, Halli SS, Cowan FM (2009) The female sex work typology in India in the context of HIVIAIDS. Trop Med Int Health 14: 673-687.
10. Buzdugan R, Halli SS, Hiremath JM, Jayanna K, Raghavendra T, et al. (2012) The female sex work industry in a district of India in the context of HIV prevention. AIDS Research and Treatment 10.

11. Beattie TS, Bradley JE, Vanta UD, Lowndes CM, Alary M (2013) Vulnerability re-assessed: The changing face of sex work in Guntur District, Andhra Pradesh. AIDS Care 25: 378-384.

12. Dodderi S, Issac S, Halli S, Krishnan S, Anderson B, et al. (2012) HIV risk among female sex workers using cell phones for solicitation in Karnataka State, South India: Implications for HIV prevention. Poster presented at AIDS 2012 Conference, Washington DC, USA.

13. Jain AK, Saggurti N (2012) The extent and nature of fluidity in typologies of female sex work in southern India: Implications for HIV prevention programs. J HIV AIDS Soc Serv 11: 169-191.

14. Mahapatra B, Saggurti N, Halli SS, Jain AK (2012) HIV risk behaviors among female sex workers using cell phone for client solicitation in India. Journal of AIDS Clinical Research 1:014.

15. Navani-Vazirani S, Solomon D, Krishnan G, Heylen E, Srikrishnan AK, et al. (2014) Mobile phones and sex work in South India: The emerging role of mobile phones in condom use by female sex workers in two Indian states. Cult Health Sex 17: 252-265.

16. Suryawanshi D, Bhatnagar T, Deshpande S, Zhou W, Singh P, et al. (2013) Diversity among clients of female sex workers in India: Comparing risk profiles and intervention impact by site of solicitation. Implications for the vulnerability of less visible female sex workers. PLoS One 8: 73470

17. Goldenberg S, Duff P, Krusi A (2015) Work environments and HIV prevention: A qualitative review and meta-synthesis of sex worker narratives. BMC Public Health 15: 1241

18. Goldenberg S, Strathdee SA, Gallardo M, Rhodes T, Wagner KD, et al. (2011) "Over here, it's just drugs, women and all the madness": The HIV risk environment of clients of female sex workers in Tijuana, Mexico. Soc Sci Med 72: $1185-1192$

19. Gysels M, Pool R, Nnalusiba B (2002). Women who sell sex in a Ugandan trading town: Life histories, survival strategies and risk. Soc Sci Med 54:179192

20. Pitpitan EV, Kalichman SC, Eaton LA, Strathdee SA, Patterson TL (2013) HIVISTI risk among venue-based female sex workers across the globe: A look back and the way forward. Curr HIVIAIDS Rep 10: 65-78.

21. Liu Q, Zhuang K, Henderson GE, Shenglong Q, Fang J, et al. (2014) The organization of sex work in low- and high-priced venues with a focus on the experiences of ethnic minority women working in these venues. AIDS Behav 18: $172-180$.

22. Ross MW, Crisp BR, Månsson SA, Hawkes S (2012) Occupational health and safety among commercial sex workers. Scand J Work Environ Health 38: $105-119$

23. Strathdee SA, Lozada R., Martinez G, Vera A., Rusch M, et al. (2011) Social and structural factors associated with HIV infection among female sex workers who inject drugs in the Mexico-US border region. PLoS One 6: 19048.

24. Reed E, Gupta J, Biradavolu M, Devireddy V, Blankenship KM (2010) The context of economic insecurity and its relation to violence and risk factors for HIV among female sex workers in Andhra Pradesh, India. Public Health Rep 4: 81-89.

25. Harcourt C, Donovan B (2005) The many faces of sex work. Sex Transm Infect 81: 201-206.

26. Heravian A, Solomon R, Krishnan G, Vasudevan CK, Krishnan AK, et al. (2012) Alcohol consumption patterns and sexual risk behavior among female sex workers in two South Indian communities. Int J Drug Policy 23: 498-504.

27. Rachakulla HK, Kodavalla V, Rajkumar H, Prasad SP, Kallam S, et al. (2011) Condom use and prevalence of syphilis and HIV among female sex workers in Andhra Pradesh, India - following a large-scale HIV prevention intervention. BMC Public Health $11: 1-10$. 


\section{UNAIDS (2014) The GAP Report. UNAIDS, Geneva, Switzerland}

29. Rodríguez DC, Krishnan AK, Kumarasamy N, Krishnan G, Solomon D, et al (2010) Two sides of the same story: alcohol use and HIV risk taking in South India. AIDS Behav 14: 136-146.

30. Stone-Romero E, Liakhovitski D (2002) Strategies for detecting moderator variables: A review of conceptual and empirical issues. Research in Personnel and Human Resources Management 21: 333-372.

31. Beattie TS, Bhattacharjee P, Ramesh BM, Gurnani V, Anthony J, et al. (2010) Violence against female sex workers in Karnataka State, South India: Impact on health, and reductions in violence following an intervention program. BMC Public Health 10: 476.

32. Subramanian T, Gupte MD, Praanjape RS, Brahmam GN, Ramakrishnan L, et al. (2008) HIV, sexually transmitted infections and sexual behaviour of male clients of female sex workers in Andhra Pradesh, Tamil Nadu and Maharashtra, India: results of a cross-sectional survey. AIDS 22: 69-79.

33. Swain SN, Saggurti N, Battala M, Verma RK, Jain AK (2011) Experience of violence and adverse reproductive health outcomes, HIV risks among mobile female sex workers in India. BMC Public Health 11: 357.

34. O'Brien RM (2007) A caution regarding rules of thumb for variance inflation factors. Quality \& Quantity 41: 673-690.
35. Buhi ER, Cook RL, Marhefka SL, Blunt HD, Wheldon C, et al. (2012) Does the Internet represent a sexual health risk environment for young people? Sex Transm Dis, 39: 55-58.

36. Horvath KJ, Nygaard K, Simon Rosser BR (2010) Ascertaining partner HIV status and its association with sexual risk behavior among Internet-using men who have sex with men. AIDS Behav 14: 1376-1383.

37. Jenness SM, Neaigus A, Hagan H, Wendel T, Gelpi-Acosta C, et al. (2010) Reconsidering the Internet as an HIVISTD risk for men who have sex with men. AIDS Behav 14: 1353-1361.

38. Lee SS, Lam AN, Lee CK, Wong NS (2012) Virtual versus physical channe for sex networking in men having sex with men of sauna customers in the city of Hong Kong. PLoS One 7: 31072.

39. Wei C, Lim SH, Guadamuz TE, Koe S (2014) Virtual versus physical spaces: Which facilitates greater HIV risk taking among men who have sex with men in East \& South-East Asia? AIDS Behav 18: 1428-1435.

40. Sanders EJ, Wahome E, Powers KA, Werner L, Fegan G, et al. (2015) Targeted screening of at-risk adults for acute HIV-1 infection in sub-Saharan Africa. AIDS 29: 221-230.

41. Shaver, FM (2005) Sex work research: methodological and ethical challeng es. J Interpers Violence 20: 296-319. 


\section{Appendix 1: Measures}

Inconsistent condom use with clients (outcome variable): Participants self-reported condom use during vaginal sex with clients in the past thirty days using a five-point response scale, ranging from 0 ' $\mathrm{Nev}$ er' to 4 'Always'. The responses were dichotomized into consistent use ('always') and inconsistent use (all other options) $(0=$ consistent, $1=$ inconsistent use).

Sex work price: Participants reported the amount of Indian Rupees (INR) from sex work received at the last client interaction (reported range: 50-5,000 INR).

Low sex work price: Constructed as a dichotomized variable, this measure reflected female sex workers who reported sex work pay at last client as 350 or less Rupees (USD 5.81), (1= less than or equal to 350 Rupees, $0=$ greater than 350 Rupees).

Client solicitation: This variable was based on participant responses to all current methods and places of client solicitation via a list of yes/no questions (e.g., street, park, bus station, beach, cinema, train station, brothel, lodge, participant's residence, friend's residence, client's residence, via pimp, drivers or family members, or via mobile phones).

Mobile phone solicitation practices were categorized into three groups: (1) Exclusive mobile phone solicitation was defined as client solicitation via mobile phones only, (2) Concurrent mobile phone/ traditional solicitation contained those FSWs who reported solicitation both via mobile phone and traditional solicitation strategies, with the latter including venues for sex work (brothels, lodges, home and public venues) and broker mediated strategies (e.g., pimps, family and drivers), and (3) No mobile phone solicitation was defined as solicitation reported only at traditional venues or via traditional methods and without mobile phones.

The classification of mobile phone solicitation was based on our conjecture that different strategies of mobile phone use result in-group level differences. As such, we report on group level findings related to demographic and occupational factors for all three FSW groups (e.g., exclusive mobile phone solicitation, concurrent mobile phone/traditional solicitation and no mobile phone solicitation).

\section{Covariates}

High frequency of sex work: A dichotomous measure of high (daily or more than once a week) versus low (once a week, monthly or during holiday periods) frequency of engagement in sex work was constructed ( $1=$ high frequency, $0=$ low frequency).

Recent STI testing: Respondents indicated whether or not they had undergone sexually transmitted infection (STI) testing in the previous three months $(1=$ tested, $0=$ not tested $)$.
Recent STI infection: Among participants who reported having been tested for STIs in the previous three months, this measure captures those reporting they received a positive diagnosis of an STI, other than HIV ( 1 = self-reported positive diagnosis, $0=$ self-reported negative diagnosis).

Ever HIV test: Participants were asked if they had ever been tested for $\operatorname{HIV}(1=$ tested, $0=$ not tested $)$.

HIV diagnosis: Respondents who indicated having ever been HIV tested, self-reported whether the test result was positive or negative ( $1=$ positive diagnosis, $0=$ negative diagnosis).

Years of sex work: His variable was constructed as a continuous variable by subtracting age at the time of survey administration with reported age at sex work debut.

FSW age: Age at time of survey administration was measured as continuous and centered at 18 years of age.

Low education: A measure was constructed to reflect participants who reported primary level of school or less versus secondary level of school or higher $(1=$ primary or lower, $0=$ secondary or higher $)$.

Slum residence: Participants were asked to identify their current type of residence ('In what type of place do you stay?'). A dichotomous measure was constructed to reflect participants who reported slum and semi-slum residence vs other places of residence. Slum residence in India is an unreliable measure of poverty given numerous challenges that keep people who have relatively stable incomes living in sub-standard areas. In this examination, slum residence is explored not as a measure of poverty but rather as an indication of environments which are defined by inadequate access to water, sanitation, privacy and violence issues related to a quality-of-life set of exposures ( $1=$ slum/semi-slum residence, $0=$ no slum/semi-slum residence).

Ever physical violence by clients: Participants were asked if they have ever experienced physical violence from clients. Responses were dichotomized to reflect those responding positively compared to those responding negatively $(1=$ ever reported client perpetrated physical violence, $0=$ no reported client perpetrated physical violence).

Recent physical violence by any sexual partner: This dichotomized measure reflected frequent actual and threats of extreme physical violence (kicked/dragged, burned/strangled, threatened or attacked with a weapon) by any sexual partner in the previous twelve months, where frequent was defined as 'often' or 'every time' ( $1=$ reported frequent physical violence by any sexual partner in previous twelve months, $0=$ no report of frequent physical violence by any sexual partner in previous twelve months). 